\title{
The Polysaccharide from the Seaweed Sargassum Graminifolium and its Effect on Calcium Oxalate Crystallization based on Determination of Electrical Conductivity
}

\author{
ZHANG Chao-yan ${ }^{1,2}$, MIAO Zhigang ${ }^{1}$, WANG Xiao-yu ${ }^{1}$, WU Wenhui ${ }^{1,2}$ \\ ${ }^{1}$ College of Food Science and Technology, Shanghai Ocean University, Shanghai 201306, China \\ ${ }^{2}$ Institutes of Marine Sciences, Shanghai Ocean University, Shanghai 201306, China
}

\begin{abstract}
The effect of sulfate polysaccharide (SGP) isolated from the seaweed Sargassum graminifolium on the growth of urinary crystal calcium oxalate ( $\mathrm{CaOx}$ ) was investigated by means of Electrical conductivity. The results showed that adding solution of SGP can inhibit on $\mathrm{CaOx}$ crystallization under the same temperature and $\mathrm{pH}$ of supersaturated solution. Moreover, increasing concentrations of SGP resulted in increased inhibiting effect on $\mathrm{CaOx}$ crystallization. Compared with control conditions, both SGP and trisodium citrate significantly inhibited $\mathrm{CaOx}$ crystallization. As we all known, trisodium citrate is used for treating and preventing urine stone. SGP contained carboxyl and hydroxyl and sulfuric acid medium through the analysis of infrared spectrum, which provided that chemical foundation for the inhibition of $\mathrm{CaOx}$. These results suggest that SGP could be a candidate for treating urinary stones because of its ability to inhibit calcium oxalate crystallization properties.
\end{abstract}

KEYWORD: Electrical conductivity; Sargassum graminifolium; polysaccharide; Infrared spectroscopy; calcium oxalate crystallization

\section{INTRODUCTION}

Calcium oxalate stone formation in vivo include the process of nucleation, growth and aggregation that is under the control of the organic matrix, the solution $\mathrm{Ca}^{2+}, \mathrm{C}_{2} \mathrm{O}_{4}{ }^{2-}$ ions interaction formed a supersaturated solution, then it gathered into clusters with Vander Waals force, electrostatic interaction and the role of particles and organic matrix molecules, after that it gradually formed crystal nucleus and gradually growled up, at last calcium oxalate crystal precipitated from it. When the precipitation of calcium oxalate appeared, the ions in solution decreased, so the electrical conductivity decreased, while the rate of decline of conductivity changes may reflect the different crystallization conditions[1]. Thus, conductivity meter can monitor the conductivity of solution real-time, electrical conductivity with the dynamic changes through time can reflect the dynamic process of crystallization of calcium oxalate crystals. There are some studies on kinetics of formation of calcium oxalate crystal by solution conductivity measurement which is a simple, cheap and not time consuming method [2].

In recent years, studies have shown that seaweed polysaccharides inhibit crystallization of calcium oxalate[3-4]. Sargassum graminifolium Turn, one of brown seaweeds extensively distributed in South China Sea and East China Sea, is common seafood and has antiallergic effect and a little other medical uses[5]. For quick comparison of the effect of sulfate polysaccharide (SGP) isolated from the seaweed Sargassum graminifolium on the growth of crystal calcium oxalate. The conductivity method also could be applied to this research.

\section{EXPERIMENTAL PROCEDURES}

\subsection{Preparation of artificial urine}

Distilled water with a small amount of disodium hydrogen phosphate $\left(\mathrm{Na}_{2} \mathrm{HPO}_{4}\right) 0.20 \mathrm{~g}$, potassium dihydrogen phosphate $\left(\mathrm{KHPO}_{4}\right) \quad 0.30 \mathrm{~g}$, sodium chloride $(\mathrm{NaCl}) 18 \mathrm{~g}$ dissolved, add distilled water volume to $1000 \mathrm{~mL}$, and mix well.

\subsection{Kinetics of Formation of calcium oxalate Crystal by Solution Conductivity Measurement}

Add $20 \mathrm{~mL}$ of $\mathrm{CaCl}_{2}$ solution at a concentration of 5 $\mathrm{mmol} / \mathrm{L}$ with $70 \mathrm{~mL}$ double-distilled water to a $200 \mathrm{~mL}$ beaker, and then mix with $20 \mathrm{~mL}$ of $\mathrm{Na}_{2} \mathrm{C}_{2} \mathrm{O}_{4}$ solution at a concentration of $5 \mathrm{mmol} / \mathrm{L}$, measure electrical conductivity of the above solution which is 
measured every 30 second. This is as a negative control. Notice that stirring with constant speed of the solution during the experiment. The sodium citrate solution was replaced with the above distilled water and the conductivity is recorded. Because sodium citrate is used widely as prevention and treatment of calcium oxalate stones in clinical medicine, it will be used as positive control. Distilled water was replaced by a solution of the SGP (concentration of $0.05 \mathrm{mg} / \mathrm{mL}, 0.1 \mathrm{mg} / \mathrm{mL}$ ). Then apply the same method to measure electrical conductivity. Each test material was prepared in triplicate.

\subsection{Infrared Spectroscopy}

Dry Sargassum graminifolium turn was obtained from Zhuhai, Guangdong province of China. Extraction of Polysaccharides from Sargassum graminifolium turn (SGP) was carried out by the our procedure ${ }^{[6]}$.Furthermore, functional groups of SGP were determined by infrared spectrum (IR).

FTIR-650 Fourier transforms infrared spectrometer (Tianjin Port East), DTGS detector, spectral resolution of $1.5 \mathrm{~cm}^{-1}$, measuring range $400 \sim 4000$ $\mathrm{cm}^{-1}$.

\section{RESULTS}

\subsection{Conductivity change with time}

Conductivity change with time in the growth of calcium was shown in Fig.1.Electrical conductivity of the $\mathrm{CaCl}_{2}$ solution which was added doubledistilled water and $\mathrm{Na}_{2} \mathrm{C}_{2} \mathrm{O}_{4}$ decreased rapidly in a short time which suggested that $\mathrm{Ca}^{2+}$ ions and oxalic acid ions rapidly aggregated because of reaction. After $3 \mathrm{~min}$ it decreased slowly, when $6 \mathrm{~min}$ it almost didn't change which showed that the reaction reaches to precipitation-Solution Equilibrium. The comparison study of electrical conductivity of the $\mathrm{CaCl}_{2}$ solution which was added sodium citrate or SGP(concentration of $0.05 \mathrm{mg} / \mathrm{mL}, \quad 0.1 \mathrm{mg} / \mathrm{mL}$ ) respectively could be seen from Kinetic curves of electrical conductivity. SGP solution is not significant compared with the same concentrations of sodium citrate solution. When added to $0.05 \mathrm{~g} /$ $\mathrm{mL}$ and $0.1 \mathrm{~g} / \mathrm{mL}$ of SGP solution, the conductivity decreased slowly kinetics, longer duration. Increasing SGP concentration, the conductivity of solution decreased more slowly. This phenomenon may be due to SGP's inhibition on crystal nucleation. The preliminary results indicate that SGP in artificial urine has some inhibition on oxalate crystallization process.

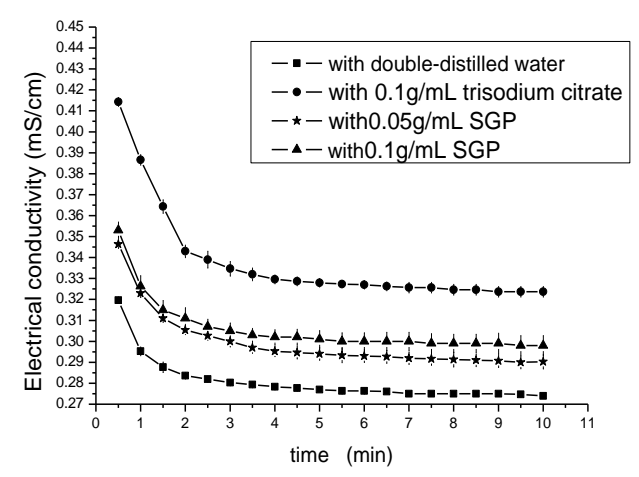

Fig 1 Conductivity change with time in the growth of calcium oxalate

\subsection{IR spectra of SGP}

Figure 2 shows that SGP in 3471, 2900, 1648 and $1253 \mathrm{~cm}^{-1}$ are absorption peaks, they are the tretching vibration of sugar ring $\mathrm{O}-\mathrm{H}, \mathrm{C}-\mathrm{H}, \mathrm{C}=\mathrm{O}$ and $\mathrm{S}=\mathrm{O}$, so this result indicates the SGP contains high sulfate content and it is consistent with chemical analysis results.

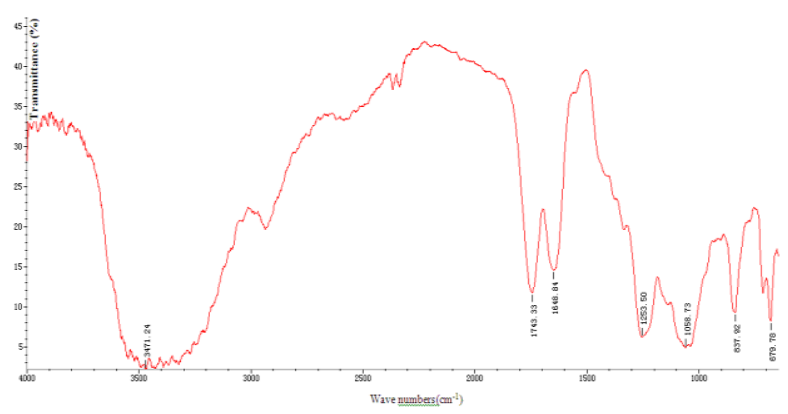

Fig 2 IR spectra of SGP

\section{DISCUSSION}

Conductivity is a measure of a material's ability to conduct an electric current and it works thanks to movable charges. Conductivity in urine is directly proportional to ionic contents. It is reported urine conductivity has a positive relation with osmolality, which is also related to sodium and uric acid concentrations. In addition, urine osmolality and conductivity levels could be used to interpret the concentration of uncharged glucose molecules. These results suggest that conductivity could be used as a parameter in routine urinalysis[7,8]. SGP has many negatively charged $-\mathrm{OSO}_{3}-,-\mathrm{COO}-$, and $\mathrm{OH}$ groups, and these anions strongly coordinate with $\mathrm{Ca}^{2+}$ ions [9]. The numerous negatively charged groups of SGP were able to chelate $\mathrm{Ca}^{2+}$ ions, resulting in a rapid increase in the concentration of $\mathrm{Ca}^{2+}$ ions on the surface of the SGP molecules. This resulted in a higher energy interface on the surface of SGP molecules. The adsorption of $\mathrm{Ca}^{2+}$ ions would result in a simultaneous decrease in free $\mathrm{Ca}^{2+}$ ions and an increase in the energy state of $\mathrm{Ca}^{2+}$ ions. Both 
the high energy interface and high energy state $\mathrm{Ca}^{2+}$ ions would then promote the formation of thermodynamically metastable COD [10]. Our findings indicate that natural substances such as SGP could contribute to the prevention of urinary stones.

\section{ACKNOWLEDGEMENT}

This research supported by special funding for the development of science and technology of Shanghai Ocean University and Doctor of philosophy

Start Fund of Shanghai Ocean University.

\section{REFERENCES}

[1] Allison JB, Anderson JA, Cole WH. 1937 .The method of electrical conductivity applied to studies on bacterial metabolism. J Bacteriol 33:645-646.

[2] Y. M. Fazil Marickar. 2008. Electrical conductivity and total dissolved solids in urine. Urological Research 36:157-232.

[3] DENG Sui-ping, OU YANG Jian-ming. 2007. Modulation of Polysaccharide Extracted from Laminaria on Phase Compositions of Urinary Crystal Calcium Oxalate. Spectroscopy and Spectral Analysi 27(11):2371-2374.
[4] WANG Miao, YU Hai-yan, OU YANG Jianming.2008.Degradation of sulfated polysaccharide from Eucheuma striatum and its inhibition on urinary mineral calcium oxalate. Marine science32 (8):34-43.

[5] Samee, H.; Li, Z.X.; Lin, H.; Khalid, J.; Wang, B.P. 2009 In vivostudy of antiallergenicity of ethanol extracts from Sargassum tenerrimum, Sargassum cervicorne and Sargassum graminifoliumTurn. Eur. Food Res. Technol. 229: 435-441.

[6] Zhang C Y, Wu W H, Wang J, et al. 2012 .Antioxidant Properties of Polysaccharide from the Brown Seaweed Sargassum graminifolium (Turn.) and Its Effects on Calcium Oxalate Crystallization. Mar. Drugs 10(1): 119-130

[7] Kavukcu S, Turkmen M, Soylu A, Kuralay F. 1998. Could conductivity be used as a parameter in urinalysis? J Pak Med Assoc. 48 (8):238-240.

[8] Felipe, H.; Susana, A. Sandra, D. 2014.Electrical conductivity measurements of urine as a new simplified method to evaluate the diuretic activity of medicinal plants. Journal of Ethnopharmacology 151:1019-1022.

[9] Kavanagh, J.P.; Jones, L.; Rao, P.N. 2000.Calcium oxalate crystallization kinetics studied by oxalate-induced turbidity in fresh human urine and artificial urine.Clin. Sci. (Lond.) 98: 151-158.

[10] Das, I.; Gupta, S.K.; Ansari, S.A.; Pandey, V.N.; Rastogi, R.P. 2005.In vitroinhibition and dissolution of calcium oxalate by edible plant Trianthema monogyna and pulse Macrotyloma uniflorum extracts. J. Cryst. Growth273: 546-554. 